\title{
CONTAMINAÇÃO DO MEIO AMBIENTE PELO DESCARTE INADEQUADO DE MEDICAMENTOS VENCIDOS OU NÃO UTILIZADOS
}

\author{
Taíse Raquel Grings Hoppe ${ }^{1}$, Luiz Ernani Bonesso de Araújo² \\ ${ }^{1}$ Especialista em Educação Ambiental da UFSM \\ 2 Professor Orientador do curso de Educação Ambiental da UFSM
}

\section{RESUMO}

Pode-se perceber que a destruição dos recursos naturais passou a ter escala praticamente exponencial a partir da Revolução Industrial. As intervenções humanas são responsáveis pela emissão de diferentes poluentes como os medicamentos descartados inadequadamente. Assim o presente estudo teve como objetivo demonstrar que, através de modificações de hábitos, podemos favorecer o meio ambiente. Para tal, deve-se descartar os medicamentos vencidos e não utilizados em lugares corretos sem causar riscos de contaminação ao meio ambiente, favorecendo a saúde e o bem estar da população. Para este estudo foram realizadas pesquisas bibliográficas em fontes primárias e secundárias para obter um levantamento sobre o destino dos medicamentos descartados. A pesquisa de campo foi realizada com uma amostra composta por 50 famílias de estudantes de $5 \underline{a}$ à 8 a séries pertencentes à comunidade escolar da Escola de Educação Básica Dom Pedro II, Agudo, RS, Brasil. Para a coleta de dados, utilizou-se a entrevista com questões semiestruturadas. Para a análise e a discussão dos resultados organizaram-se levantamentos e gráficos. Frente aos resultados obtidos na pesquisa sobre os medicamentos descartados, pode-se concluir que a maior parte da população descarta os medicamentos inadequadamente por não saber os malefícios que estes causam ao meio ambiente e também pelo fato de não ter um local correto para serem descartados.

Palavras-chaves: educação ambiental; solo; água; descarte; medicamentos.

\section{ABSTRACT}

Can be notice that the destruction of natural resources start to have a exponential scale starting from the Industrial Revolution. The human intervention is responsible by emission of different pollutants as the inadequate discard drugs. So this study had for objective show that by habits changes we can favor the environment. For this we need be discard de expire or not use drugs in adequate places without cause risks for the environment favoring the population health and welfare. For this study were realized bibliographic research's in primary and secondary sources for obtain one lifting about the destination of discard drugs. The field research was realized with one sample of 50 basics students families belonging to the scholar community of the Dom Pedro II Basic Education School, Agudo, RS, Brazil. For the data collecting was utilized a interview with semi-structured questions. For the results analyze and discussion organized lifting and graphics. In front the results obtained by the research about discard drugs can conclude that larger part of population discard inadequately the drugs because don't know about the harms that this drugs cause for the environment and too because don't have a adequate place for drugs discard.

Key-words: environmental education; soil; water; discard; drugs 


\section{INTRODUÇÃO}

Os problemas ambientais ganharam destaque no mundo a partir da Revolução Industrial, porém a sociedade atual ainda não está dando a importância devida às questões ambientais.

Para Ferreira (2005) "a nossa civilização chega ao limiar do século XXI como a civilização dos resíduos, marcada pelo desperdício e pelas contradições de um desenvolvimento industrial e tecnológico sem precedentes na história da humanidade" $(2005$, p.1), pois o problema não está relacionado ao fato de não saber do que está acontecendo com o meio ambiente, mas sim na forma de interpretar e compreender a situação ambiental, sendo a natureza utilizada para eliminar os dejetos.

Sabe-se que o aquecimento global e outros fatores de contaminação estão relacionados a todos esses acontecimentos, no entanto este estudo tem como foco fazer uma análise do destino dos medicamentos descartados no município de Agudo, esclarecendo à comunidade as sérias consequências que o descarte inadequado pode causar ao ambiente.

Considera-se um sério problema ambiental a quantidade de resíduos gerados pelas indústrias, pois a capacidade de regeneração do meio ambiente é bem menor e mais lenta, do que a produção de resíduos. Assim, para superar a lógica econômica insustentável decorrente da visão cartesiana torna-se necessária uma nova percepção que oriente uma racionalidade ambiental. (LEFF, 2006)

Os resíduos produzidos causam poluição ambiental provocando um desequilíbrio do ambiente natural. Entre estes resíduos está a preocupação do destino final dos medicamentos não utilizados, sendo esse um problema que se insere em um contexto abrangente e complexo.

Assim, devido ao grande risco social resultante do descarte inadequado de medicamentos e a falta de conscientização sobre os mesmos, este estudo buscará levantar dados para ampliar conhecimentos sobre esta temática assim como uma forma de despertar e sensibilizar a comunidade agudense que o uso de medicamentos deve ser racional e necessita-se dar um destino adequado a esses medicamentos sem prejudicar o meio ambiente.

No entanto é necessário que a educação ambiental aproxime a humanidade com a natureza, gerando vínculos emocionais a fim de permitir ampliação de percepções e até mudanças de atitudes.

Para tal, alunos realizaram uma pesquisa com uma amostra constituída por 50 entrevistados, entre eles, pais, familiares e alunos da comunidade escolar da Escola de Educação Básica Dom Pedro II sobre as características sócio demográficas, quanto ao hábito de consumo de medicamentos e quanto à consciência ambiental sobre o descarte de medicamentos vencidos ou não utilizados.

Dessa forma esse estudo justifica-se pela necessidade de informar a comunidade agudense que o descarte inadequado dos medicamentos vencidos ou não utilizados pode causar sérios problemas de contaminação ao meio ambiente. Muitas vezes, por falta de informação, as pessoas não se dão conta que atitudes inadequadas podem prejudicar o meio em que vivem e as consequências poderão refletir na vida de cada ser humano influenciando negativamente na sua saúde e no bem estar. Diante dessa problemática pretende-se promover a formação de conhecimentos, mudanças de atitudes e conscientizar a comunidade agudense que a colaboração de cada indivíduo é importante para ajudar a diminuir as agressões ao meio no qual vivemos.

Sendo assim, a realização desse estudo busca um ser consciente de seus atos, que desenvolva ações e mudanças de atitudes no descarte de medicamentos e assim contribua com a melhoria de vida e saúde na comunidade, obtendo com isso um ambiente saudável e sustentável. 


\section{REVISÃO DE LITERATURA}

No decorrer da história de políticas mundiais vêm sendo interligadas as questões de saúde e de meio ambiente, com o intuito da promoção da saúde, através da colaboração ativa de todos os cidadãos no descarte de medicamentos. No entanto ainda hoje persiste o desafio de organizar estudos para identificar, avaliar e analisar as ações coletivas para bem estar das pessoas através de um ambiente saudável.

Em nossa contemporaneidade existe uma preocupação hesitante em relação aos efeitos da degradação ambiental no mundo, sendo que nosso país não tem um destino adequado para os medicamentos descartados, resíduos químicos que causam problemas de contaminação no meio ambiente.

De acordo com Alvarenga / Nicoletti (2010),

o Brasil está entre os maiores consumidores mundiais de medicamentos e com a sua economia estável agregada ao maior acesso a medicamentos, estabelecido pelas políticas governamentais adotadas, contribuem para o aumento do consumo que trará como consequência, maior quantidade de embalagens e sobras de medicamentos que terão como destino o lixo comum. (2010, p.35)

Então, pode-se dizer que a condição da saúde está relacionada com o contexto socioambiental. Se há um ambiente limpo e sadio para conviver, logo será também propício à saúde, pois conforme Alvarenga / Nicoletti (2010), além da geração de resíduos o descarte doméstico de medicamentos são questões para ser amplamente discutidas e estudadas em nível de saúde pública em que é necessária a responsabilidade coletiva para minimizar o uso excessivo de medicamentos pela população.

No entanto, todos têm o direito de viver em um ambiente saudável, mas para isso é preciso a colaboração do coletivo na preservação e na manutenção dos recursos naturais. Para tanto, as ações essenciais consistem em preservar e cuidar, para alcançar melhores condições de vida. Para que esses cuidados com o meio se transformem em ações concretas, é preciso conscientização e mudanças de atitudes.

Portanto, entende-se que, por meio da Educação Ambiental, é possível desenvolver um trabalho interdisciplinar, em que se agregue significações para cada gesto honesto com a natureza.

\section{Medicamentos descartados são resíduos}

Os medicamentos vencidos e descartados são considerados resíduos, que apresentam riscos à saúde humana e ao meio ambiente, principalmente a água e ao solo.

Conforme Silvestri (2006),

até os medicamentos que não são descartados e são consumidos (como parte do processo de recuperação da saúde) acabam sendo eliminados no meio ambiente. Fármacos de diversas classes terapêuticas, como antibióticos, hormônios, anti-inflamatórios entre inúmeras outras têm sido detectados em esgoto doméstico, águas superficiais e subterrâneas. (2006, p.35)

No entanto, o tratamento e a destinação final dos resíduos ainda se resumem na adoção de soluções imediatas, que geralmente se restringem no simples descarte, predominando os depósitos a céu aberto que contribuem para a destruição ambiental.

Segundo Alvarenga / Nicoletti (2010), a legislação existente sobre o descarte de medicamentos se direciona aos estabelecimentos de saúde e não engloba a população em geral o 
que dificulta o entendimento sobre os impactos decorrentes do descarte doméstico, no qual a população elimina os medicamentos no lixo comum gerando resíduos.

Conforme Rodrigues (2009), "vale ressaltar que a realidade sanitária do país, com infraestrutura precária, ausência de aterros sanitários, é outro fator que dificulta os de tratamento adequado de resíduos de natureza biológica ou química." (2009, p.80)

\section{Descarte inadequado dos medicamentos por falta de informação}

$O$ destino dos medicamentos que sobram de tratamentos finalizados e dos que são comprados em quantidades desnecessárias são guardados para serem utilizados novamente. Assim, a falta de tempo para ir ao médico ou a carência de atendimento de consultas gratuitas, ou o acreditar que não é necessário procurar um médico faz com que se utilizem prescrições anteriores. (GASPARINI, 2010)

O mesmo autor afirma que a população é a peça chave na solução dos problemas causados pelos medicamentos quando inadequadamente descartados no ambiente. Porém, para que esse papel seja exercido de forma consciente e absoluta, é necessária a educação juntamente com a consciência ambiental e o acesso à informação ambientalmente correta, para que assim, com essa informação, possa exercer, de forma plena, a defesa da sustentabilidade.

Ainda, conforme Gasparini (2010), “o descarte inadequado é feito pela maioria das pessoas por falta de informação e divulgação sobre os danos causados pelos medicamentos ao meio ambiente e por carência de postos de coleta". (2010, p.42)

Para tal, a falta de informação faz com que as pessoas descartem esses medicamentos no lixo comum ou em vasos sanitários, mas conforme Sottoriva (2009), o sistema de esgoto brasileiro não está preparado para fazer o tratamento adequado de resíduos tóxicos provenientes de medicamentos que são atirados na pia ou no vaso sanitário.

Existem algumas tendências básicas quanto às tentativas de minimização desses resíduos: reciclagem, incineração completa e aterros sanitários.

No entanto, o descarte inadequado de medicamentos vencidos pode causar sérias intoxicações no ser humano e também no meio ambiente. "Os remédios têm componentes resistentes que se não forem tratados acabam voltando para nossa casa e a gente pode até consumir água com restos de remédios. Eles são produtos químicos e não podem ser jogados no lixo comum". (NASCIMENTO, 2008, p. 01)

\section{Uso racional de medicamentos}

O uso racional de medicamentos é uma questão que vem sendo discutida pela população em que a adequação posológica ao número de unidades seria uma das soluções para minimizar o consumo excessivo de medicamentos.

De acordo com Gasparini (2010), os medicamentos são essenciais para a manutenção da saúde da população, porém, a mídia dá um grande incentivo ao consumo excessivo de medicamentos e isso faz aumentar o acúmulo de medicamentos não utilizados nas residências.

$\mathrm{Na}$ verdade são vários fatores que influenciam o consumo de medicamentos, entre eles pode-se citar a propaganda, a oferta de medicamentos, as doenças, as prioridades do sistema de saúde e suas estruturas. Sabe-se que a publicidade é, sem dúvida, o fator predominante para o uso racional, pois a indústria farmacêutica gasta boa parte de seu orçamento em publicidade e acaba convencendo a população da cura de doenças utilizando certos medicamentos. O consumo de medicamentos, como já citado, também está relacionado com os recursos econômicos e humanos destinados ao serviço de saúde, no qual no Brasil existem programas de saúde que 
distribuem gratuitamente a maioria dos medicamentos básicos para diversos tratamentos de saúde, sendo que esta distribuição gratuita é importante para quem realmente necessita de medicamentos, mas também é um incentivo para o consumo exagerado sem real necessidade de um tratamento.

De acordo com Laporte (1985), existem muitos medicamentos inúteis, em que a sua eficácia terapêutica jamais foi comprovada, sendo que alguns são usados para tratamento de problemas que têm raízes sociais e não podem ser resolvidos com remédios, mas os fabricantes e as farmácias exercem pressão para expandir constantemente o mercado sem procurar preencher uma necessidade real.

Portanto, o uso racional de medicamentos indica observância do princípio de que a não geração de resíduos incluídos a estes os medicamentos, passa pelo adequado gerenciamento na fabricação, distribuição, venda e prescrição dos mesmos. Para adequar o consumo à produção crescente de tecnologias, a sociedade contemporânea necessita encurtar cada vez mais a temporalidade das ações, eliminando a durabilidade dos bens e tornando-os rapidamente substituíveis. O medicamento moderno é parte dessa sociedade que, por meio de significados simbólicos, também produz necessidades de consumo que devem incorporar os bens que são produzidos em escala.

No entanto, para o consumo de medicamentos é necessário observar sua validade e aparência, pois medicamentos utilizados fora desse prazo podem causar efeitos indesejados e oferecer riscos à saúde. Segundo a ANVISA (Agência Nacional de Vigilância Sanitária), o prazo de validade de um medicamento corresponde ao tempo durante o qual o produto poderá ser usado, caracterizado como período de vida útil e fundamentada nos estudos de estabilidade específicos. (ANVISA, 2010)

Portanto, enquanto os medicamentos vencidos aguardam a mobilização das condições adequadas de descarte, devem permanecer em recipientes adequadamente identificados em locais discriminados dos demais e também identificado para impedir de forma inequívoca que sejam utilizados inadequadamente.

\section{Destino final dos medicamentos}

A sociedade atual enfrenta um grande problema, pois mesmo sabendo que os medicamentos não devem ser descartados em qualquer lugar do meio ambiente não existe um destino correto para os mesmos.

Segundo Silva (2005), desde tempos mais remotos, há registros históricos de que as pessoas fazem uso de remédios com alguma finalidade seja aliviar dores, prevenir ou curar doenças ou até mesmo na alteração do humor, mas de forma inadequada, se automedicando e descartando os medicamentos que restam do tratamento em lugares não adequados.

A destinação final dos resíduos de medicamentos ainda se resume na adoção de soluções imediatas, em que quase sempre são fundamentadas no simples descarte, predominando o descarte no lixo comum, pois conforme Silva (2005), "lixo nada mais é do que o reflexo da sociedade que o produz, quanto mais industrializada, rica tem-se mais resíduos pelo fato de consumir mais", (2005, p.15), e assim contribuindo na contaminação do meio ambiente.

A incineração de resíduos sólidos seria o destino adequado para os medicamentos que necessitam ser descartados, pois segundo Bidone (2005) a incineração é um processo de oxidação à alta temperatura que destrói ou reduz o volume ou recupera materiais ou substâncias, ou seja, transformar os rejeitos em materiais inertes, reduzindo peso e volume.

De acordo com Alvarenga / Nicoletti (2010), 
a incineração é atualmente a maneira indicada para destino e diminuição do volume dos medicamentos inutilizados, como método de evitar que estes sejam descartados indevidamente no ambiente, trazendo como consequências a poluição de água e solo, devemos considerar que a incineração por sua vez não é o método ideal, uma vez que gera emissão de gases tóxicos à atmosfera. $(2010$, p.38)

No entanto, existem dificuldades que apenas poderão ser superadas com a integração de todos os envolvidos nessa questão. Segundo Silva (2005), para tentar solucionar a questão da quantidade de lixo, propõe-se uma mudança no comportamento social, principalmente nos padrões de produção e consumo com a diminuição de medicamentos descartados.

Na Resolução $n^{\circ} 44$ de 17 de agosto de 2009, a ANVISA dispõe no artigo 93 que fica permitido às farmácias e drogarias participar de programas de coleta de medicamentos a serem descartados pela comunidade com o intuito de preservar a saúde pública e a qualidade do meio ambiente. Porém, não há legislação específica para cobrar desses estabelecimentos à realização destas campanhas, atribuindo então a responsabilidade para a comunidade em devolver a esses lugares os medicamentos não utilizados.

Conforme a legislação brasileira, as farmácias não têm a obrigação de receber remédios que não serão mais usados. Já os postos de saúde não podem aceitar os medicamentos, mesmo dentro da data de validade, porque não é possível saber como eles foram armazenados.

Os órgãos de saúde sabem que o problema existe, mas pouco fazem para solucioná-lo. As normas existentes dizem respeito aos estabelecimentos de serviços de saúde. Porém, ainda não foram editadas normas que abranjam o consumidor final com relação ao descarte de medicamentos, pois os estados e municípios têm autonomia para criar as próprias leis que estabeleçam a forma correta de se descartar os remédios.

Uma prática a ser adotada seria realizar a incineração, pois os compostos formados ficam inertes, ou seja, não reagem e dessa forma não acarretam riscos à natureza. Apesar das altas temperaturas garantirem o processo, a vigilância sanitária exige testes no material após incineração para garantir e documentar o procedimento.

Para que a incineração fosse uma solução, os medicamentos descartados deveriam ser encaminhados a empresas autorizadas pela vigilância sanitária. Porém, de acordo Sottoriva (2009), o problema do descarte incorreto de medicamentos vencidos pelos cidadãos se dá pela falta de divulgação sobre os problemas causados ao meio ambiente e também da carência de postos de coleta. Infelizmente eles ainda são restritos nas cidades brasileiras e algumas unidades de saúde ainda não estão preparadas para lidar com essa situação.

A melhor solução seria o investimento na melhoria contínua do processo e da estrutura para impedir que os produtos se tornem inservíveis (por vencimento ou deterioração) durante o tempo de estocagem.

Essas mudanças e desastres não se restringem apenas ao ambiente físico e biológico, mas também as relações sociais, econômicas e culturais. Para tal, Silva (2005) afirma que "enquanto o homem não se conscientizar que faz parte do meio ambiente e que não está acima deste, a natureza será cada vez mais prejudicada, porém se houver tal consciência irá ocorrer uma integração saudável e satisfatória para ambos levando ao equilíbrio". (2005, p. 8) 
Monografias Ambientais

(e-ISSN: 2236-1308)

REMOANFSM

\section{METODOLOGIA}

Trata-se de uma pesquisa descritiva e exploratória, explicada por Sacramento (2008), como "comum em situações em que se pretende confirmar a viabilidade de um problema cientificamente pesquisável, aumentar a familiaridade com esse problema e construir hipótese(s)". (2008, p.39)

Essa pesquisa foi concretizada com atividades desenvolvidas com trabalho de campo, em uma escola do município de Agudo, em que as atividades estavam relacionadas ao descarte de medicamentos vencidos ou não utilizados.

Do ponto de vista da natureza trata-se de uma pesquisa participativa, no qual a comunidade participa na análise de sua própria realidade, a fim de promover uma transformação social em benefício dos participantes.

Essa pesquisa faz uma abordagem qualitativa, visando às características e o problema a ser estudado.

O objeto principal desse estudo engloba o destino final dos medicamentos descartados relevando os aspectos legais e ambientais, em que as mudanças de atitudes e hábitos são fundamentais para prevenir riscos à saúde e ao meio ambiente.

A pesquisa bibliográfica foi realizada em fontes primárias e secundárias a fim de levantar o destino dos medicamentos descartados e os riscos causados à saúde humana e ao meio ambiente.

Segundo Carvalho (1991), pesquisa bibliográfica "é a atividade de localização e consulta de fontes diversas de informação escrita, para coletar dados gerais ou específicos a respeito de um determinado tema". (1991, p.110) Esse estudo prévio pode trazer contribuições para a inserção dos pesquisadores no local de pesquisa, propondo uma práxis coerente, aliando teoria e prática, ao conhecimento elaborado por outros pesquisadores e que se reelabora com a pesquisa em questão.

Na sequência, foi realizado um levantamento do destino dos medicamentos vencidos e não utilizados em bibliografias eletrônicas e impressas. As atividades foram selecionadas e elaboradas de acordo com o contexto da comunidade escolar atingida nesse projeto.

Todas as pesquisas foram adaptadas para a compreensão dos alunos, sendo que através deles, a conscientização ambiental do destino final e correto do descarte dos medicamentos vencidos e não utilizados seja repassada para a comunidade.

a) Apresentação do projeto: "A contaminação do meio ambiente pelo descarte inadequado de medicamentos vencidos ou não utilizados", para a direção da escola e para os alunos, dialogando sobre o assunto para interação e preocupação do mesmo.

b) Levantamento das concepções dos alunos relacionadas ao destino dos medicamentos descartados e problemas causados ao ambiente e à saúde pelo seu descarte.

c) Publicação de um artigo sobre o projeto no jornal da região, Jornal Deutsche Integration, de 19 a 25 de agosto de 2011, no337/Edição 594, pois foram encontrados medicamentos no lixo numa cidade vizinha, no qual, aproveitou-se a oportunidade para repassar a preocupação sobre o descarte de medicamentos para comunidade da região, ou seja, leitores do jornal acima descrito.

As atividades realizadas com os alunos foram as seguintes:

a) Pesquisa realizada com a família e alguns dos alunos de 5a à $8^{a}$ série sobre características sócio demográficas, hábitos de consumo de medicamentos e algumas concepções sobre os problemas causados pelo descarte inadequado. 
b) Após a pesquisa os alunos da 6a série realizaram o levantamento de dados dos 50 entrevistados e foram ao laboratório de informática e construíram os gráficos dos resultados obtidos no programa Microsoft Excel.

c) Num outro momento os alunos da 5 a série foram divididos em quatro grupos, fizeram uma análise dos resultados e criaram uma mensagem em Powerpoint com informações sobre o destino correto e as precauções que devemos adotar para não contaminar o ambiente com o descarte de medicamentos. Esta mensagem foi enviada através do correio eletrônico (email), em que cada aluno enviou a mensagem para, ao menos, 20 destinatários.

Nessa fase foram avaliadas as percepções dos estudantes, relativo ao descarte de medicamentos e sobre a preocupação em manter um meio ambiente sustentável e sadio.

Para a pesquisa, foi adotada a abordagem qualitativa, utilizando-se da lógica da compreensão dos fenômenos por sua descrição e interpretação, a partir da observação direta dos participantes nas práticas ambientais, nesse caso, a criação e divulgação dos emails.

\section{RESULTADOS E DISCUSSÃO}

Após analisar os dados obtidos, surgiu a oportunidade de observar algumas das características sócio demográficas dos entrevistados, entre as quais chamou a atenção que, entre os entrevistados, pode-se afirmar que o grau de escolaridade é elevado, pois dos entrevistados, 24\% estão cursando o Ensino Fundamental, 4\% possuem o Ensino Fundamental completo, $6 \%$ estão cursando o Ensino Médio, 26\% possuem o Ensino Médio completo, $20 \%$ estão cursando o Ensino Superior e a mesma taxa percentual, 20\%, possui o Ensino Superior completo, mostrado na figura a seguir.

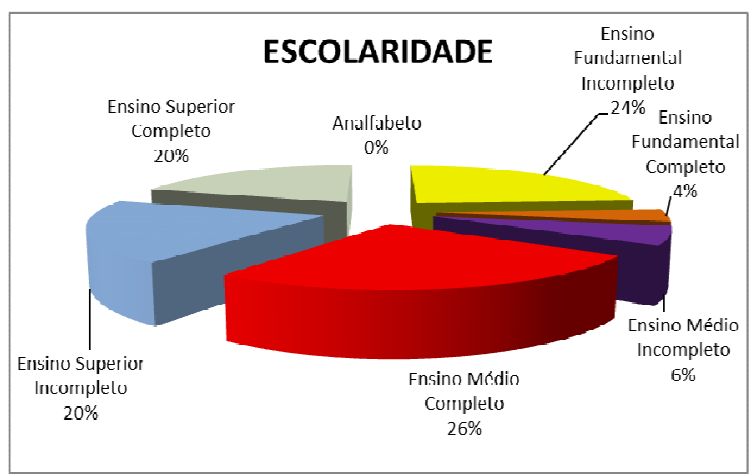

Figura 1. Grau de escolaridade. Fonte: Autor (2011)

Sobre o questionamento dos hábitos quanto ao consumo de medicamentos, consideraram-se determinadas questões pertinentes, tais como: $96 \%$ dos entrevistados possuem medicamentos em casa, conforme (Figura 2), em que geralmente fazem uso desses medicamentos sem consultar o médico, no qual $70 \%$ às vezes se automedicam (Figura 3 ), talvez sem necessidade. 


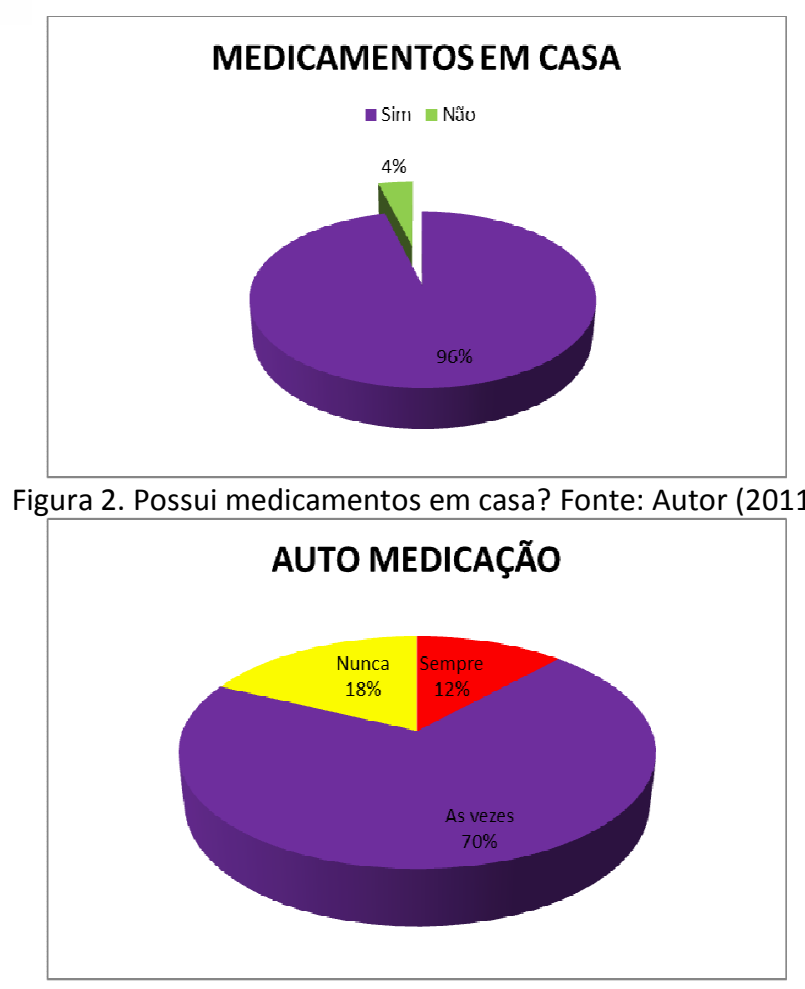

Figura 3. Você costuma se automedicar? Fonte: Autor (2011)

Na pergunta referente ao descarte das sobras dos medicamentos, pode-se perceber que $48 \%$ dos entrevistados guardam os medicamentos para serem reutilizados e $32 \%$ põe esses medicamentos no lixo domiciliar (Figura 4), no qual $76 \%$ dos entrevistados possuem medicamentos vencidos em casa (Figura 5), sendo que, esses têm como destino o lixo que é levado a aterros sanitários comuns, não recebendo o tratamento adequado de incineração e assim, contaminando o meio ambiente pelos resíduos químicos que os compõe.

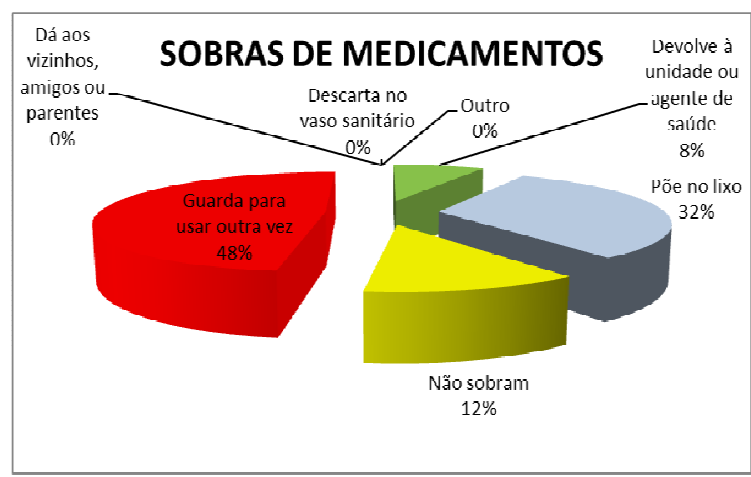

Figura 4. O que faz com as sobras de medicamentos? Fonte: Autor (2011) 


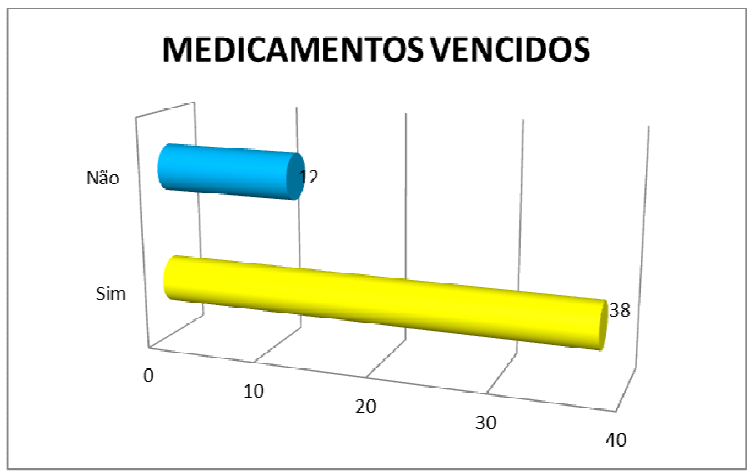

Figura 5. Possui medicamentos vencidos? Fonte: Autor (2011)

Percebe-se que existe a conscientização dos entrevistados, pois todos acreditam que o descarte de medicamentos pode causar problemas ambientais (Figura 6) e que os medicamentos deveriam ser vendidos na dosagem exata conforme a prescrição do médico (Figura 7).

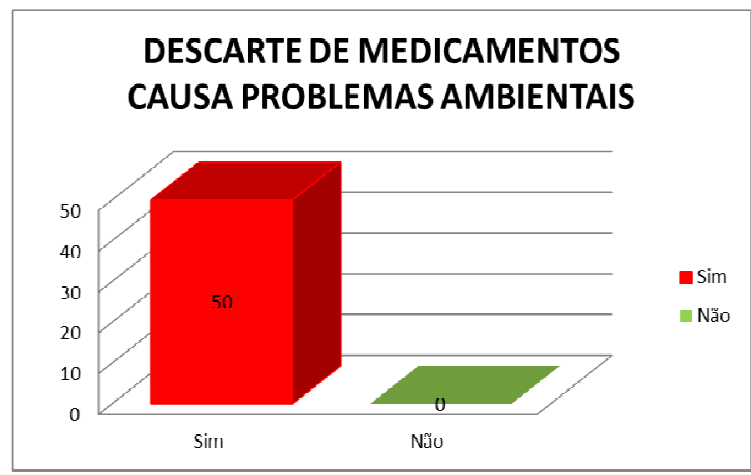

Figura 6. Você acredita que o descarte de medicamentos pode causar problemas ambientais? Fonte: Autor ( 2011)

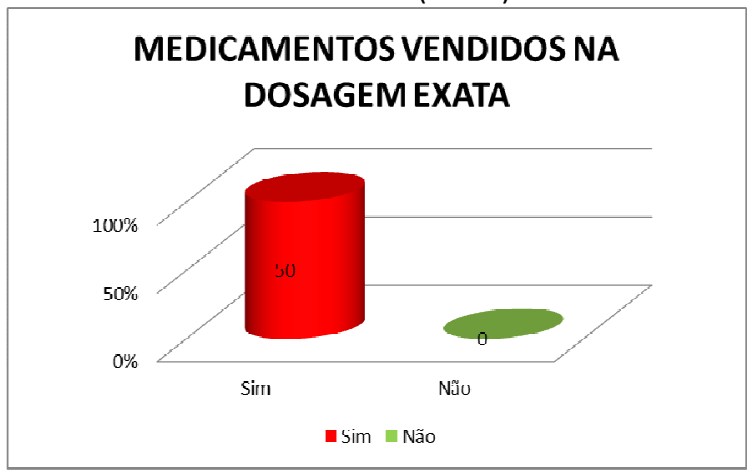

Figura 7. Os medicamentos deveriam ser vendidos na dosagem exata conforme a prescrição do médico? Fonte: Autor (2011)

Conforme a pesquisa, $90 \%$ dos entrevistados afirmam que os culpados de descartar incorretamente os medicamentos somos nós, veja na figura a seguir. 


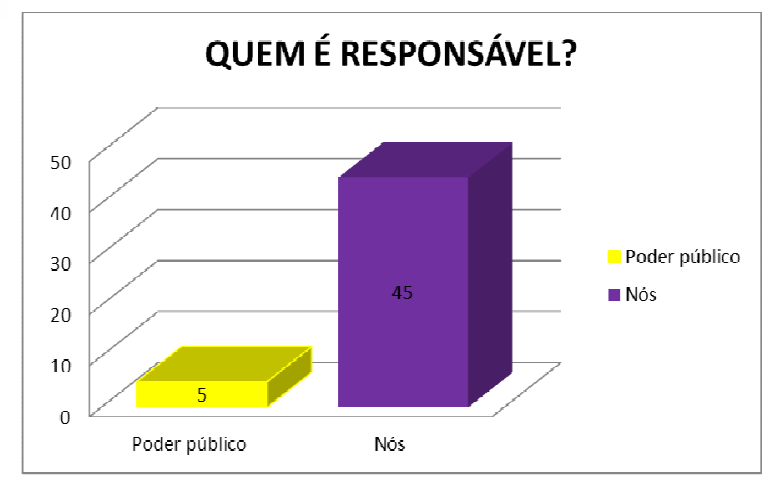

Figura 8. Se sim, quem é responsável? Fonte: Autor (2011)

Os entrevistados estão conscientes que esse descarte causa problemas ambientais, mas muitas vezes utilizam esse método de descarte por não ter outra opção, conforme mostrado na figura abaixo.

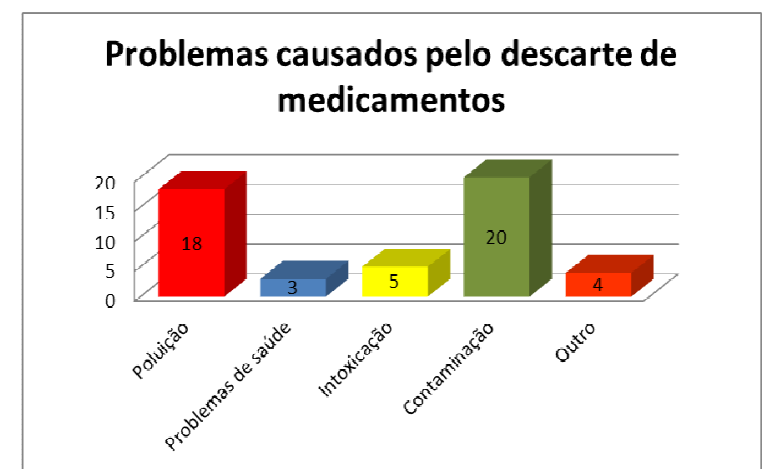

Figura 9. Quais problemas ambientais são causados pelo descarte de medicamentos?

Fonte: Autor (2011)

Diante desses resultados acredita-se que as mídias e o mercado influenciam o consumidor a comprar cada vez mais medicamentos, em que esse consumo exagerado auxilia nas sobras de medicamentos e no descarte inadequado.

As informações à população sobre o descarte de medicamentos mostra que esse é um assunto muito distante da realidade e conhecimento da sociedade, pois $70 \%$ nunca foram orientados sobre o assunto, conforme mostrado na figura a seguir. 


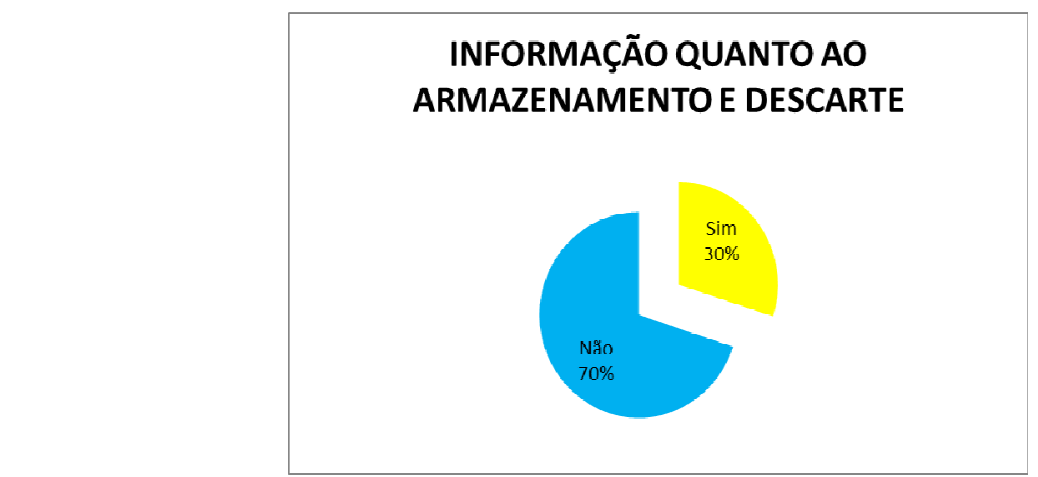

Figura 10. Já recebeu alguma informação sobre o descarte e armazenamento de medicamentos? Fonte: Autor (2011)

No entanto, estamos diante de um problema de contaminação gravíssima, no qual a maioria da população nem percebe as sérias consequências desse descarte inadequado. As medidas de prevenção ambiental são cobradas por lei, mas nada se faz quanto a esses resíduos químicos que se juntando a outros formam uma quantidade potencialmente perigosa.

\section{CONSIDERAÇÕES FINAIS}

Ao finalizar este trabalho, considera-se a relação com o meio ambiente tão importante quanto à sua preservação. Assim, a contaminação dos recursos ambientais por medicamentos descartados pode causar um grande impacto ambiental.

As tecnologias e a inteligência humana não são eficientes para os impactos que estão sendo causados ao meio ambiente. Portanto, a partir desse trabalho foi possível contemplar os estudantes mostrando-lhes que as iniciativas individuais são fundamentais para a conscientização da humanidade, em que a ação de cada indivíduo é de extrema importância para ajudar a preservar os recursos naturais.

Entre os aspectos positivos do trabalho, destaca-se a preocupação dos alunos quanto ao descarte correto dos medicamentos e a participação ativa nas atividades propostas, expondo suas concepções.

Através da pesquisa realizada pode-se concluir que a comunidade está consciente dos problemas causados pelo descarte inadequado dos medicamentos, mas o fazem por muitas vezes não ter alternativa. Para tal, a sociedade humana precisa intervir imediatamente buscando alternativas para diminuir essa contaminação que vem acontecendo num aumento gradativo com resultados assustadores e drásticos, em que a própria humanidade está sofrendo com as manifestações causadas pelos diversos tipos de poluição. Assim, esse trabalho evidenciou a necessidade de leis mais específicas quanto ao descarte de medicamentos.

Por outro lado, pode-se afirmar que é necessário um maior rigor na fiscalização e aplicabilidade das leis já existentes. Também vale ressaltar que a realidade sanitária de nosso país tem uma infraestrutura precária, sendo este outro fator que dificulta os processos de tratamento de resíduos adequadamente. Logo, precisa-se de atitudes para diminuir esse tipo de contaminação favorecendo tratamentos adequados aos medicamentos descartados.

No entanto, as discussões permitiram troca de conhecimento e experiência entre os participantes que dessa forma construíram seu conhecimento, mas pode-se perceber que é necessário resgatar no ser humano a conscientização de que cada indivíduo precisa agir para 
ajudar a diminuir as agressões causadas ao meio ambiente, sendo que as mudanças de atitudes de cada um irão fazer a diferença em que o destino dos medicamentos descartados representa um imenso desafio à capacidade tecnológica e humana. Essas mudanças e desastres não se restringem apenas ao ambiente físico e biológico, mas também às relações sociais, econômicas e culturais.

Considera-se que esse trabalho serviu para ampliar as percepções da autora e dos participantes da pesquisa, no qual acredita-se que a educação ambiental é uma das melhores formas de conscientizar a população sobre os problemas que essas ações humanas podem causar a sociedade.

Assim, ter-se-á como resposta ao trabalho, a visão dos adultos (famílias) e das crianças em relação às dinâmicas desenvolvidas que objetivavam fazer perceber as possíveis contribuições que a Educação Ambiental poderá oferecer em relação à promoção da saúde.

Ao final desse trabalho sinto-me honrada em ter contribuído como educadora ambiental para transmitir o conhecimento adquirido nas disciplinas ofertadas no curso de educação ambiental e assim dizer que é através da vivência com a natureza que a humanidade deverá repensar na sua ação cotidiana frente ao ambiente.

\section{REFERÊNCIAS BIBLIOGRÁFICAS}

ALVARENGA, L.S.V./ NICOLETTI, M.A. Descarte Doméstico de Medicamentos e algumas considerações sobre o Impacto Ambiental. Revista Saúde, 2010.

ANVISA. Agência Nacional de Vigilância Sanitária. Disponível em:<http://www.anvisa. gov.br/ medicamentos/glossario/glossario_p.htm>. Acesso em 08 de outubro de 2011.

BIDONE, Francisco Antonio. Resíduos Sólidos Provenientes de Coletas Especiais: Eliminação e Valorização. Disponível em:<http://www.finep.gov.br/prosab/livros/ prosabbidonefinal.pdf>. Acesso em 01 de outubro de 2011.

CARVALHO, Maria Cecília M. de. (org). Construindo o saber: metodologia científica, fundamentos e técnicas. São Paulo: Papirus, 1991.

FERREIRA, J. A. Resíduos sólidos e lixo hospitalar: Uma discussão ética. Cad.Saúde Públ. v.11 n.2, Rio de Janeiro, abr./jun. 2005.

GASPARINI, J.C.; GASPARINI, A. R.; FRIGIERI, M.C. Estudo do descarte de medicamentos e consciência ambiental no município de Catanduva-SP. Disponível em:<http://www.fatecjab.edu. br/revista/2011_v02_n01/4_gasparini.pdf >. Acesso em 13 de outubro de 2011.

LAPORTE, Joan-Ramon. Para Melhor Uso de Medicamentos - Disponível em:<http://www.taps org.br/Paginas/medmedic04.html>. Acesso em 15 de novembro de 2011.

LEFF, Enrique. Racionalidade Ambiental - a reapropriação social da natureza. Civilização Brasileira, 2006. 
REMOANFSM

NASCIMENTO, Carlos Eduardo. Descarte de Remédios: uma questão muito grave. Disponível em:<htp://planetasustentavel. abril.com.br/noticia/lixo/conteudo_296191.shtml>.

Acesso em 15 de outubro de 2011.

RODRIGUES, Carla R. B. Aspectos Legais e Ambientais do Descarte de Resíduos de Medicamentos. Disponível em:<http:// www.pg.utfpr.edu.br/dirppg/ppgep/dissertacoes/ arquivos/121/Dissertacao.pdf $>$.Acesso em 22 de setembro de 2011.

SACRAMENTO, Weverton Pereira do. Metodologia da Pesquisa Científica. Ouro Preto, MG:UFOP, 2008.

SILVA, Evelyn Ribeiro. Problematizando o Descarte de Medicamentos Vencidos: para onde destinar? Disponível em:< http://www.epsjv.fiocruz.br/beb/Monografias2005/evelyn.pdf >. Acesso em 01 de outubro de 2011.

SILVESTRI, Cezar. Destinação Final dos Medicamentos Vencidos. Disponível em: <http://www.al.rs.gov.br/download/ComEspMedicamentosVencidos/Relat\%C3\%B3rioFinal.pdf $>$. Acesso em 18 de outubro de 2010.

SOTORIVA, Patricia. Descarte Incorreto de Medicamentos Ameaça o meio Ambiente. Disponível em: < http://www.medicsupply.com.br/pacientes/blog/descarte-incorreto-de-medicamentosameaca-meio-ambiente/>. Acesso em 16 de outubro de 2011. 
Monografias Ambientais

(e-ISSN: 2236-1308)

REMOANFSM

Questionário da Pesquisa

1) Sexo: ( ) Masculino ( ) Feminino

2) Idade:

3) Escolaridade:

( ) Analfabeto ( ) Ensino fundamental incompleto ( ) Ensino fundamental completo

( ) Ensino médio incompleto ( ) Ensino médio completo ( ) Ensino superior incompleto

( ) Ensino superior completo

4) Possui medicamentos em casa: ( ) Sim ( ) Não

5) No respectivo medicamento, há presença de bula?

( ) Sim ( ) Não ( ) Somente alguns

6) Observa o aspecto/aparência e a data de validade do medicamento antes de utilizá-lo?

( ) Sim ( ) Não

7) $\mathrm{O}$ que faz com as sobras dos medicamentos?

( ) Devolve à unidade ou ao agente de saúde ( ) Guarda para usar outra vez

( ) Põe no lixo ( ) Dá aos vizinhos/amigos/parentes

( ) Não sobram ( ) Descarta no vaso sanitário Outro:

8) Possui medicamentos vencidos: ( ) Sim ( ) Não

O que faz com eles?

9) Você acredita que o descarte de medicamentos pode trazer problemas ambientais:

( ) $\operatorname{Sim}$ ( ) Não

Se sim quem é o responsável?

10) Já recebeu alguma informação quanto ao armazenamento e descarte de medicamentos?

( ) Sim ( ) Não

11) Se você acha que o descarte de medicamentos causa problemas, qual ou quais problemas você acha que esse descarte pode causar?

12) Você acha que os medicamentos deveriam ser vendidos na dosagem exata conforme a prescrição do médico?

( ) $\operatorname{sim}$ ( ) Não

13) Você costuma se auto medicar?

( ) Sempre ( ) As vezes ( ) Nunca 